\title{
Comparison of temporal fluctuations in the total electron content estimates from EISCAT and GPS along the same line of sight
}

\author{
B. Forte ${ }^{1}$, N. D. Smith ${ }^{1}$, C. N. Mitchell ${ }^{1}$, F. Da Dalt ${ }^{1}$, T. Panicciari ${ }^{1}$, A. T. Chartier ${ }^{1}$, D. Stevanovic ${ }^{2}$, M. Vuckovic ${ }^{2}$, \\ J. Kinrade ${ }^{1}$, J. R. Tong ${ }^{1}$, I. Häggström ${ }^{3}$, and E. Turunen ${ }^{4}$ \\ ${ }^{1}$ University of Bath, Bath, UK \\ ${ }^{2}$ University of Nova Gorica, Nova Gorica, Slovenia \\ ${ }^{3}$ EISCAT Scientific Association, Kiruna, Sweden \\ ${ }^{4}$ Sodankylä Geophysical Observatory, Finland \\ Correspondence to: B. Forte (b.forte@bath.ac.uk)
}

Received: 15 October 2012 - Revised: 12 March 2013 - Accepted: 18 March 2013 - Published: 23 April 2013

\begin{abstract}
The impact of space weather events on satellitebased technologies (e.g. satellite navigation and precise positioning) is typically quantified on the basis of the total electron content (TEC) and temporal fluctuations associated with it. GNSS (global navigation satellite systems) TEC measurements are integrated over a long distance and thus may include contributions from different regions of the ionised atmosphere which may prevent the resolution of the mechanisms ultimately responsible for given observations. The purpose of the experiment presented here was to compare TEC estimates from EISCAT and GPS measurements. The EISCAT measurements were obtained along the same line of sight of a given GPS satellite observed from Troms $\varnothing$. The present analyses focussed on the comparison of temporal fluctuations in the TEC between aligned GPS and EISCAT measurements. A reasonably good agreement was found between temporal fluctuations in TEC observed by EISCAT and those observed by a co-located GPS ionospheric monitor along the same line of sight, indicating a contribution from structures at $\mathrm{E}$ and $\mathrm{F}$ altitudes mainly to the total TEC in the presence of ionisation enhancements possibly caused by particle precipitation in the nighttime sector. The experiment suggests the great potential in the measurements to be performed by the future EISCAT_3D system, limited only in the localised geographic region to be covered.
\end{abstract}

Keywords. Ionosphere (auroral ionosphere; instruments and techniques) - radio science (space and satellite communication)

\section{Introduction}

The total electron content (TEC) integrated along the line of sight of a given radio link is associated with group delay and phase advance resulting from the propagation of a radio signal throughout the ionised part of Earth's atmosphere (Davies, 1965). With the advent of satellite-based technologies, such as satellite telecommunications and satellite-based navigation and precise positioning applications (hereafter, GNSS), our society has become increasingly more reliant on those systems, which may be critically vulnerable to disruptive space weather events.

The impact of space weather events on satellite-based navigation and telecommunication systems may be subdivided into two categories: (a) the distortions introduced by large-scale inhomogeneities in the spatial distribution of the plasma density and (b) the disruption introduced by smallscale structures, by means of the phenomenon known as radio wave scintillation. The former has been typically analysed on the basis of TEC measurements and TEC temporal fluctuations which may be associated with degradation of positioning accuracy in the case of satellite navigation applications (Mannucci et al., 1998; Schaer, 1999; Jakowski et al., 2002).

TEC measurements typically deduced from observations of GNSS radio signals are utilised to calculate TEC maps which may be at local (http://swaciweb.dlr.de) or global scale (http://aiuws.unibe.ch/ionosphere/, http://iono.jpl.nasa. gov, http://swaciweb.dlr.de). An important aspect connected with this operation is the absolute calibration of TEC 
observations against offsets introduced for example by clock errors, cycle slips, and phase ambiguity (Ciraolo et al., 2007). A further complication is introduced by the conversion of TEC measurements corresponding to slant ray path into values corresponding to vertical ray paths, in order to increase the map coverage (Meggs et al., 2004). Calibrated TEC measurements are also used in tomographic imaging of the upper ionised atmosphere (Bust and Mitchell, 2008; Yin et al., 2008; Yizengaw et al., 2006a, b). Similarly to the approach used in the case of maps, tomographic images rely on calibrated slant TEC measurements, which are then used to reconstruct 2-D or 3-D images by assuming a theoretical model for the electron density vertical profile (Bust and Mitchell, 2008, and references therein).

Previous analyses compared TEC estimates obtained by the integration of electron density profiles obtained by the EISCAT (http://www.eiscat.se) receiver in Troms $\emptyset$ with verticalised TEC estimates obtained from GPS stations nearly co-located with the radar and the ionosonde (Lilensten and Cander, 2003; Lilensten et al., 2005; Pokhotelov et al., 2011; Stolle et al., 2006). In those cases, the incoherent scatter radar measured electron density profiles in a direction parallel to the local magnetic field line. The electron density profiles were calibrated against two nearly co-located ionosondes, and the TEC estimate was obtained by integrating the electron density profiles from $90 \mathrm{~km}$ up to $498 \mathrm{~km}$. The results of the comparison showed instances of substantial agreement between GPS TEC and EISCAT TEC together with cases of disagreement where GPS TEC appeared lower than the EISCAT TEC (Lilensten and Cander, 2003). The origin of discrepancies was hypothesised to rely on factors such as localised particle precipitation enhancing EISCAT TEC estimates, slant GPS satellites' lines of sight cross-cutting areas of particle precipitation resulting in underestimated TEC, and the protonospheric contribution after geomagnetic storms (Lilensten and Cander, 2003; Lunt et al., 1999).

A different analysis showed a comparison between EISCAT TEC obtained by integration of electron density profiles and verticalised GPS TEC from nearly co-located stations, with equivalent ionospheric pierce points overlapping the area covered by EISCAT (Jakowski et al., 1996). In that case, EISCAT was operated in a scanning mode (CP3) and electron density profiles were measured at different latitudes between 62 and $78^{\circ} \mathrm{N}$ during a $30 \mathrm{~min}$ north-south scan. GPS TEC estimates as from TEC maps were then compared with EISCAT TEC within an overlapping region. The EISCAT TEC was obtained by integration of CP3 electron density profiles from about $150 \mathrm{~km}$ to about $500 \mathrm{~km}$ height and then verticalised at ionospheric pierce points by means of a mapping function (Jakowski et al., 1996). The results indicated larger GPS TEC as compared with EISCAT TEC values, given the geometry considered, which suggested a plasmaspheric contribution not captured by the radar, yet present on GPS radio signals (Jakowski et al., 1996).
On the basis of these previous analyses, the present experiment was proposed. Within the framework of the ongoing Marie Curie Initial Training Network TRANSMIT (http:// www.nottingham.ac.uk/transmit), $25 \mathrm{~h}$ of measurement time were allocated to the proposed experiment. The measurements took place from 12 December 2011 to 16 December 2011 between 15:00 UT and 19:00 UT approximately every day. The UHF EISCAT radar in Troms $\varnothing$ was made to point towards given GPS satellites. The idea was to follow a GPS satellite and to compare temporal fluctuations in EISCAT TEC estimates (obtained by integration of electron density profiles along the line of sight) and in GPS TEC estimates from the tracked satellite, in order to gather more evidence in addition to what was shown earlier. This approach avoided indeed any assumption about verticalisation or absolute calibration of TEC measurements by providing possible insights on the influence of D/E layers, F layer and topside (and the problem of disentangling them on GPS TEC measurements). The measurements were carried out during quiet magnetic conditions; however this type of experiment repeated in more active conditions might reveal additional details. Here, the results of only one day of measurement were reported, namely those from Troms $\emptyset$ on Monday 12 December 2011. The results suggest the potential advantage of using EISCAT_3D (http://www.eiscat3d.se) measurements for the investigation of physical processes over different spatial and temporal scales as well as for their application to satellitebased technologies exposed to adverse space weather events.

\section{Data and methodology}

The position of GPS satellite PRN23 was determined in advance on the basis of the projection of the ephemeris in the future by using a SP3 file (http://igscb.jpl.nasa.gov/igscb/ data/format/sp3_docu.txt) released the day before each of the days during the measurement campaign. Those positions were determined at $5 \mathrm{~min}$ intervals to cover the entire duration of the measurement. PRN23 was followed between 16:00 UT and 18:00 UT. The radar was pointed towards the same satellite by remaining fixed in a given position (defined in terms of azimuth and elevation) for $5 \mathrm{~min}$, then repositioning in the new direction in the next interval, and so on. During each position the GPS satellite was moving and traversing the radar line of sight during each $5 \mathrm{~min}$ interval. During each $5 \mathrm{~min}$ interval the radar was measuring and collecting backscattered power, which was then converted into electron density profiles by using the typical GUISDAP analysis toolbox (http://www.eiscat.com/groups/Documentation/ UserGuides/GUISDAP/).

For the sake of completeness, estimates of calibrated GPS slant TEC were calculated as well on the basis of ray tracing through reconstructed electron density structures, following the inversion procedure detailed in Mitchell and Spencer (2003) and subsequently refined in Chartier et al. (2012). 
The inversion method produced three-dimensional images of electron density. The intersections of a given ray path with the electron density images were used to calculate the slant TEC along the given ray path. Two different calibration methods were utilised. The first method ("daily calibration") assumes slant TEC extracted from the images should match the GPS observations when no local structuring is present. The second method ("weekly calibration") calculates slant TEC along a given ray path for the whole week of measurements; the average difference between imaged slant TEC and observed slant TEC provides a calibration constant. Both methods provide estimates for the GPS slant TEC accurate within few TECU. However, the point here was to appreciate and quantify the sensitivity of the two instruments in the presence of ionospheric structures (and their evolution) by means of temporal fluctuations in TEC along the same line of sight, which can provide possible insights on the separate influence of D/E layers, F layer and topside on GPS TEC measurements.

\subsection{EISCAT calibration}

Typically, EISCAT electron density profiles are calibrated against closest available ionosondes by means of the calibration script CALIB_NE within GUISDAP (Lehtinen and Huuskonen, 1996) (http://www.eiscat.com/groups/ Documentation/UserGuides/) in view of similar geometries between the two instruments (e.g. vertical or field-aligned directions) allowing for common fields of view on average. In the case of the present experiment, the calibration of electron density profiles along slant lines of sight by means of CALIB_NE was purely indicative, owing to different fields of view between instruments. A refined calibration could have been based on the use of possible ionosonde measurements centred at the equivalent ionospheric pierce point coordinates for the radar positions. However, in this case one limitation would have been the availability of such instruments across the whole interval of directions the radar pointed to, and a second limitation would have been introduced by the slant projection of vertical profiles. That type of calibration was not attempted for the analysis presented here, and the standard CALIB_NE toolbox was applied to EISCAT measurements by allowing the minimum elevation angle to be $60^{\circ}$. This choice was not entirely appropriate as the minimum elevation angle should be limited to $75^{\circ}$. However owing to the particular geometry used in this experiment, CALIB_NE was used to remove possible outliers from the data and increase the confidence in the slant electron density profiles and their accuracy. An example of the output of CALIB_NE for the measurements collected during this experiment is shown in Fig. 1 where the actual proportionality between EISCAT and ionosonde data is indicated together with the suggestion for the calibration constant to be used for obtaining calibrated EISCAT electron density profiles. The analysis to follow was entirely based on calibrated electron density profiles accord-

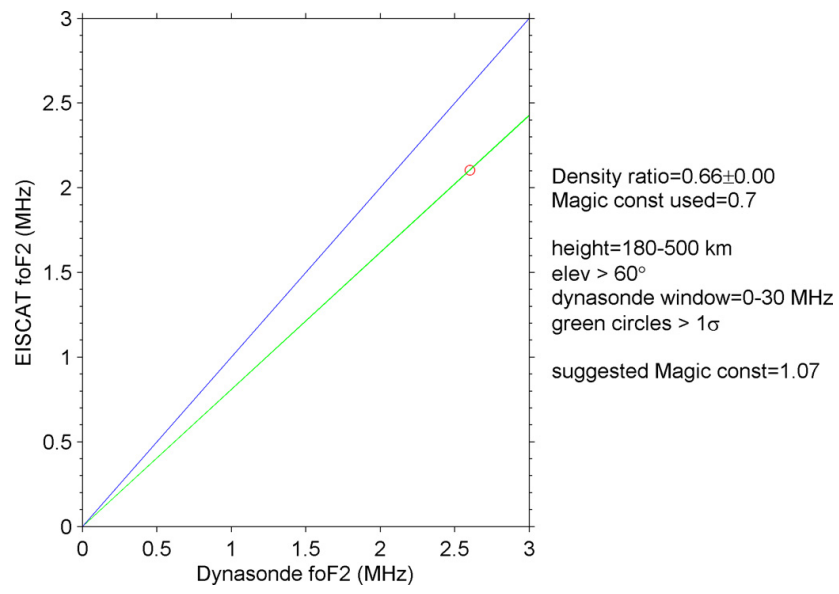

Fig. 1. Calibration of EISCAT electron density profiles by means of ionosonde measurements, according to the algorithm CALIB_NE.

ing to what is described above. Another aspect to consider is that ionosonde data from the $\mathrm{F}$ region are usually missing when the $\mathrm{E}$ layer is dense (as in the case of sporadic $\mathrm{E}$ layers).

\subsection{Time alignment}

Co-located with the EISCAT radar was a Novatel GSV4004 ionospheric monitor capable of measuring TEC and rate of change of TEC at $1 \mathrm{~min}$ intervals together with $50 \mathrm{~Hz}$ signal level and phase (Van Dierendonck et al., 1993). The comparison of the rate of change of TEC between GPS and EISCAT relied on the integration of EISCAT slant electron density profiles. EISCAT electron density profiles could be obtained at different integration times during each radar position. The maximum integration time was approximately $5 \mathrm{~min}$, corresponding to the duration of the measurements in one precise position. The maximum integration time corresponded to the minimum error in the electron density profiles possible in the case of the experiment considered here. Figure 2 shows a representative case of electron density profiles, the error associated with them, and the estimate of the electron temperature profiles for an integration time corresponding to 5 min (Fig. 2a), $60 \mathrm{~s}$ (Fig. 2b) and $150 \mathrm{~s}$ (Fig. 2c). The error on the electron density profiles increased with decreasing integration time, especially at higher ranges. For the sake of the comparison between rate of changes of GPS TEC and EISCAT TEC, an integration time of $150 \mathrm{~s}$ was chosen as the most appropriate compromise between temporal averaging and confidence in the measurements. All the calculations shown hereafter refer to EISCAT electron density profiles obtained by means of $150 \mathrm{~s}$ integration time.

\subsection{Data processing}

The tracked satellite (PRN23) provided TEC measurements, which were compared with the radar's one. In view of the error connected with electron density profiles at $150 \mathrm{~s}$ 

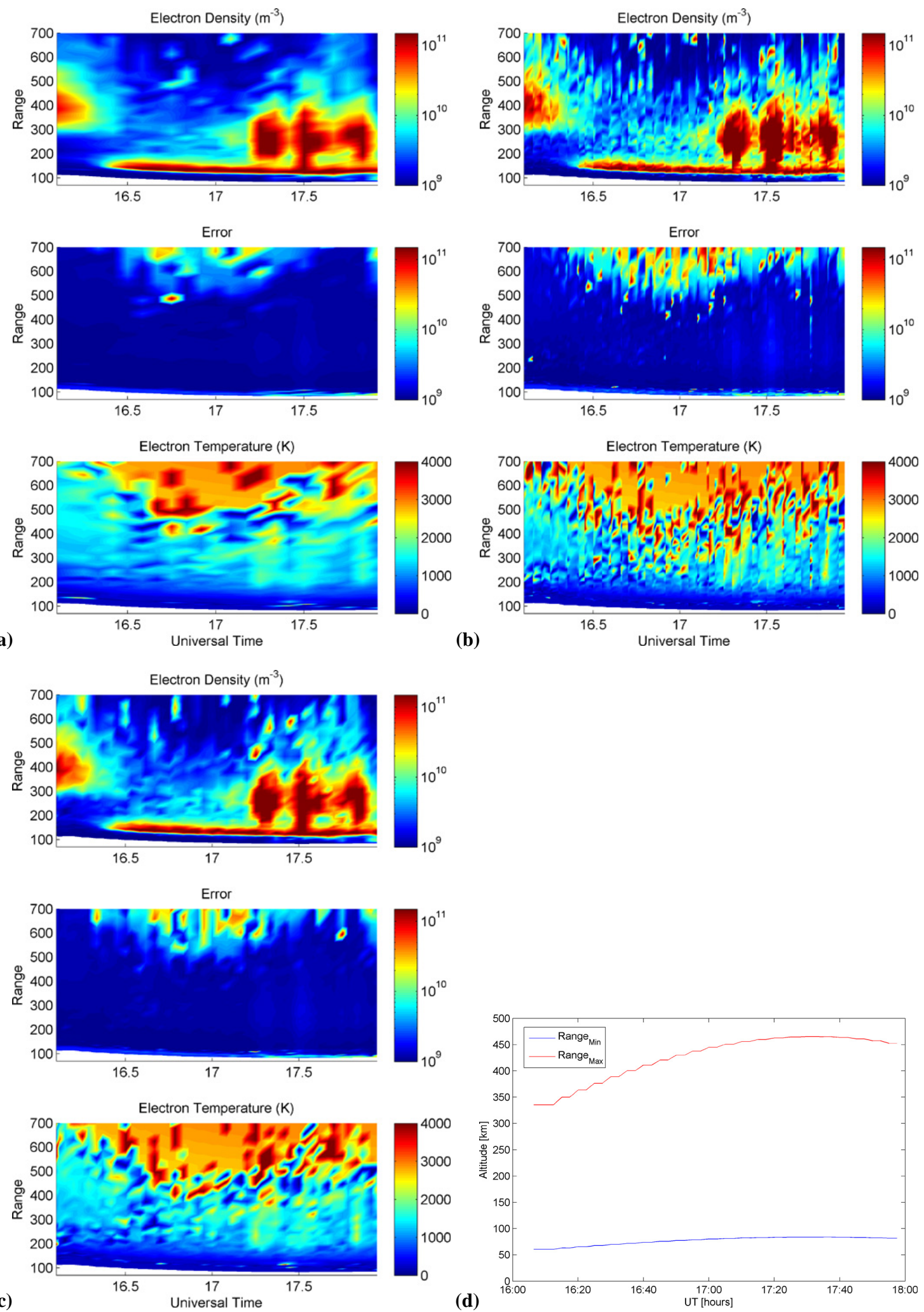

Fig. 2. Different integration times, evaluation of errors and integration ranges: (a) $5 \mathrm{~min}$; (b) $60 \mathrm{~s}$; (c) $150 \mathrm{~s}$; (d) vertical altitudes corresponding to EISCAT ranges in the case of 12 December 2011. 


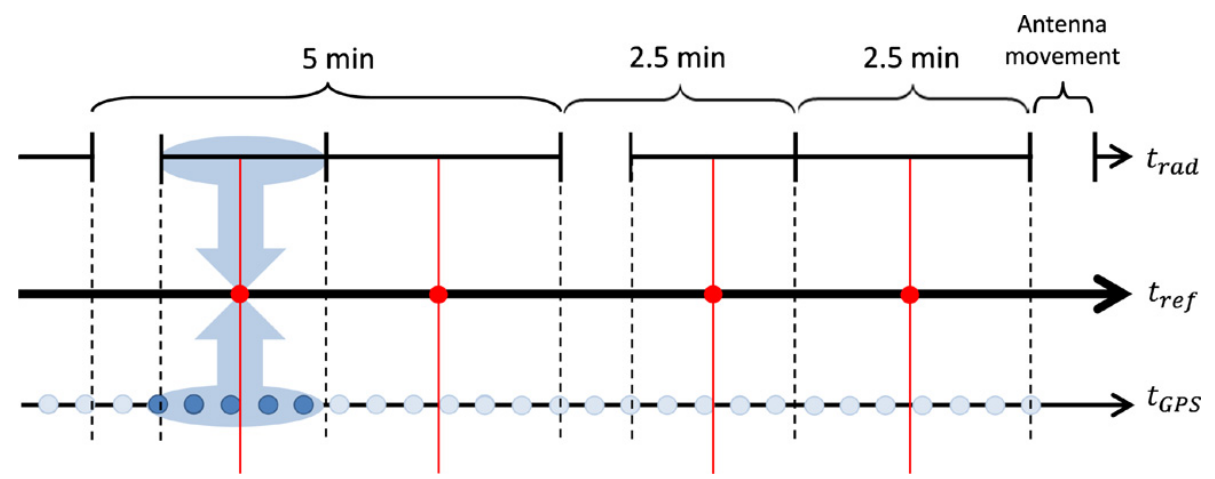

Fig. 3. The two GPS and radar data sets have different time axes $\left(t_{\mathrm{rad}}\right.$ and $\left.t_{\mathrm{GPS}}\right)$. The reference time axis $\left(t_{\mathrm{ref}}\right)$ used in the further analysis corresponds to the central point of the radar interval time (about $2.5 \mathrm{~min}$ without considering the antenna movement time). The GPS values used in the analysis are taken from the average of the samples (about 10 every $2.5 \mathrm{~min}$ ) inside the radar time measurement window.

integration time, the EISCAT TEC was calculated by integrating the electron density profiles from $70 \mathrm{~km}$ up to $500 \mathrm{~km}$ in range. Because the interest was in the comparison between rates of changes of TEC (estimates of GPS slant TEC were calculated in two different ways), the observation times needed to be as close as possible. While the GPS TEC values were supplied every $15 \mathrm{~s}$, the radar sampling rate corresponded, instead, to the integration time used to retrieve the TEC at $150 \mathrm{~s}$. It has to be considered that, to follow the satellite, the radar antenna moved every $5 \mathrm{~min}$ and, because the movement takes a few seconds, the actual measurement time interval could be smaller than $150 \mathrm{~s}$.

Furthermore, the two sampling times were not aligned. There were about 10 GPS samples in each radar measurement interval (a rate of $15 \mathrm{~s}$ in about a $150 \mathrm{~s}$ interval) which needed to be reduced and aligned with the radar data according to a communal reference time. The GPS samples were then averaged in that interval. Each average value was then referenced to a time corresponding to the centre of the radar measurement interval (Fig. 3). Details of the error analysis are given in Appendices A and B.

\section{Results and discussion}

Figure $2 \mathrm{c}$ shows measurements from EISCAT (Tromsø) on 12 December 2011, in terms of electron density profiles, the error associated with them, and the electron temperature profiles. Figure $2 \mathrm{~d}$ shows the minimum and maximum altitudes corresponding to EISCAT ranges utilised for the TEC integration while following PRN23. Figure 4a shows the TEC obtained by integration of the electron density profiles in Fig. 2c, integrating from $70 \mathrm{~km}$ altitude to the maximum altitude in Fig. 2d. In addition, Fig. 4a contains estimates of the GPS slant TEC along the same line of sight calibrated according to the "daily" and "weekly" methods described in Sect. 2 (in this particular case, the "daily" method provided a better calibration against the "weekly" method). Figure 4b shows temporal fluctuations in TEC as observed by both the radar and the GPS monitor over a time interval of $150 \mathrm{~s}$. In Fig. 4b, different lower bounds for the TEC integration were used and compared with the GPS observations. Figure $4 \mathrm{c}$ shows the contribution to temporal fluctuations in TEC from different ionospheric layers (i.e. D/E, F1 and F2 nominally in terms of altitude intervals) as compared to the GPS observations. Figure 5 refers to PRN23 tracked between 17:00 UT and 18:00 UT on 16 December 2011.

The normal ionisation decay between 16:00 UT and 16:30 UT (Fig. 2c) was followed by a sporadic E (Es) layer which formed at approximately 16:20 UT and lasted throughout the measurement interval (Kirkwood and Nilsson, 2000; Nygrén et al., 1984). Typically, about 2 TECU of integrated ionisation could be associated with that Es layer (Fig. 4a). At 17:10 UT an enhancement in the ionisation at higher ranges showed three distinct peaks (i.e. at 17:15 UT, at 17:30 UT and at 17:50 UT), with the Es layer still present underneath (Fig. 2c). The integrated ionisation corresponding to those ionisation enhancements corresponded to about 5-7 TECU (Fig. 4a). The ionisation enhancement might have originated from plasma patches transported over the line of sight (Foster et al., 2005; Moen et al., 2006).

Such a pattern can be observed as well through the electron density integrated along the path (i.e. TEC) as measured from EISCAT (Fig. 4a), where enhancements in TEC can be associated with enhanced ionisation structures appearing in Fig. 2c. The integration ranges utilised in the calculation of TEC as observed from the radar (Fig. 2d) included altitudes typical for both $\mathrm{E}$ and $\mathrm{F}$ regions. Consequently, temporal fluctuations in slant EISCAT TEC along the radar line of sight in correspondence with the ionisation enhancements (compare Figs. 2c and 4b) seemed to be correlated with temporal fluctuations in the TEC observed from PRN23 (Fig. 4b). Different contributions are shown in Fig. 4b: temporal fluctuations in TEC after integrating electron density profiles from $70 \mathrm{~km}$ in altitude (blue line), from $150 \mathrm{~km}$ in altitude (red line), and from $200 \mathrm{~km}$ in altitude (green line). 
(a)

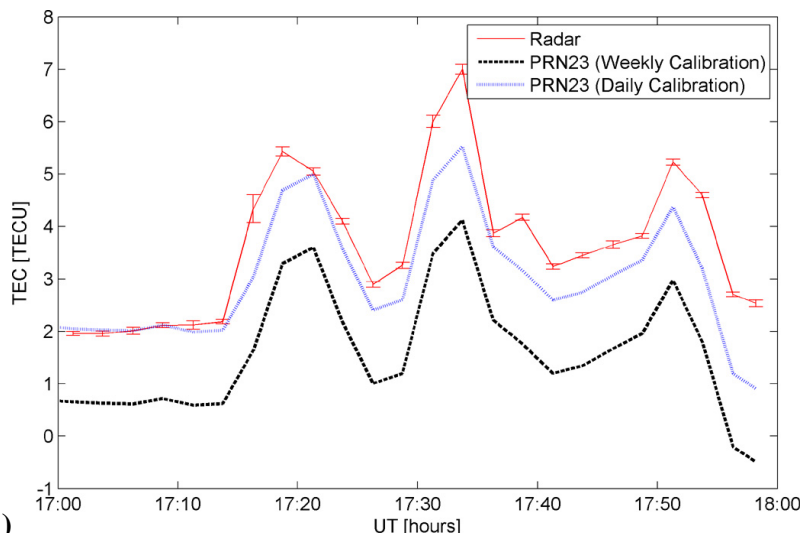

(b)

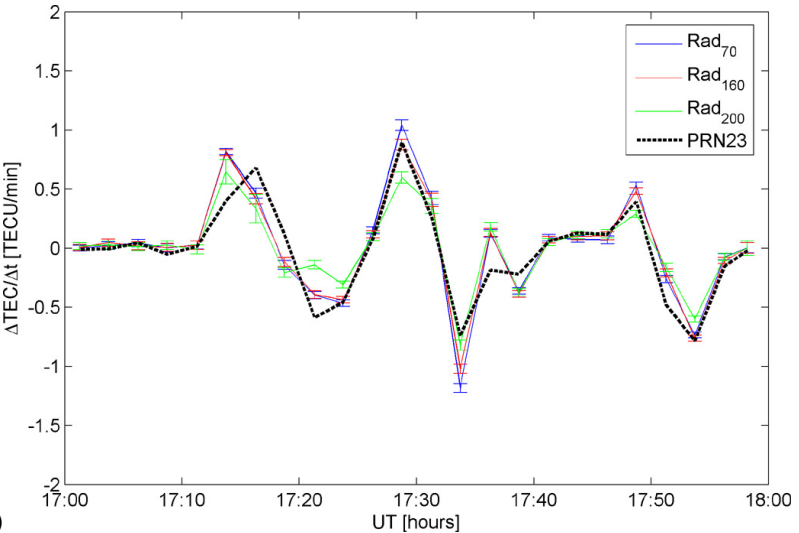

(c)

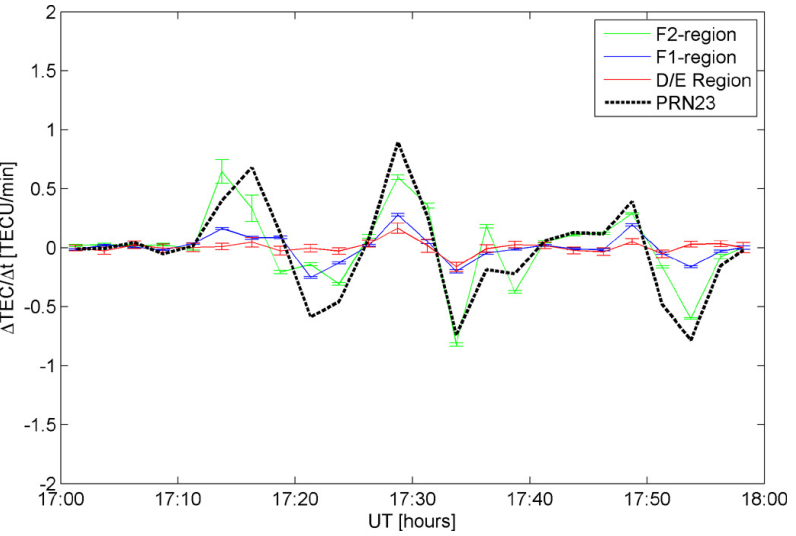

Fig. 4. Comparison of slat TEC and its temporal fluctuations between radar and GPS for the measurements from Troms $\varnothing$ on 12 December 2011. (a) Slant TEC as obtained from EISCAT (Troms $\varnothing$, 12 December 2011) electron density profiles integrated between $70 \mathrm{~km}$ altitude and $500 \mathrm{~km}$ range in comparison with estimates of the GPS TEC along the same line of sight. (b) Temporal fluctuations in slant TEC along the EISCAT (Troms $\varnothing, 12$ December 2011) line of sight as integrated from altitudes $70 \mathrm{~km}$ (blue), $150 \mathrm{~km}$ (red), $200 \mathrm{~km}$ (green) upwards until range $500 \mathrm{~km}$. Temporal fluctuations in slant TEC from PRN23 (dashed black) along the same direction are shown as well. The temporal fluctuations are calculated over an interval of approximately $150 \mathrm{~s}$. (c) Contributions to temporal fluctuations in TEC from different ionospheric layers (i.e. D/E, F1 and F2 nominally) in comparison with the overall GPS TEC fluctuations (Troms $\varnothing, 12$ December 2011). The temporal fluctuations are calculated over an interval of approximately $150 \mathrm{~s}$.
TEC fluctuations obtained when integrating from $200 \mathrm{~km}$ in altitude (Fig. 4b) seemed to be similar to the fluctuations obtained when integrating from $70 \mathrm{~km}$ or $150 \mathrm{~km}$ in altitude, suggesting the bulk of ionisation causing TEC enhancements was located at $F$ layer altitudes. In order to verify such an aspect, the contributions to TEC fluctuations from radar observations were isolated from different ionospheric layers (Fig. 4c): i.e. from altitude intervals nominally associated with D/E (70-150 km), F1 (150-200 km) and F2 layers (200 km to maximum range). The largest contribution appeared to result from the F2 layer (Fig. 4c), while the whole TEC fluctuations observed from PRN23 would include the contributions from each different layer with its own phase (different phases might stem, for example, from layers mixing along the line of sight as observed in Swartz et al. (2009) for example). The comparison between Fig. $4 \mathrm{~b}$ and $\mathrm{c}$ suggests that the bulk of TEC fluctuations originated in the $\mathrm{F}$ region with nothing attributed to the topside or to a redistribution of plasma in the plasmasphere in this specific case.

The differences in TEC fluctuations observed from the radar and PRN23, within the time period of Fig. 4b and c, are within \pm 0.5 TECU over $150 \mathrm{~s}$. This may reflect different sensitivities to different regions, but further studies would be required.

The experiment described here was intended to provide possible clues on the real structuring along the line of sight as compared with integrated GPS measurements. Satellite data can indeed be used for 3-D imaging on either regional or global scales, while present EISCAT profiling is limited to narrow regions and to specific temporal windows with different sensing geometries (see for example a comparative study in Meggs et al., 2005). The modelling of structured features such as those described here might equip tomography reconstruction algorithms with higher resolution, which is needed to infer the physics of the observed phenomena. On the other hand, from a purely applicative point of view, the measurements performed by both GPS and EISCAT showed a substantial agreement which could illustrate the great potential behind the measurements to be performed by the future EISCAT_3D instrument (Aikio et al., 2012; Johansson et al., 2010). Of course, the results reported are dependent on the accuracy of the EISCAT calibration using ionosondes; there is scope for improvement especially under Es layers such as those reported in this experiment.

In view of the experiment described here, EISCAT_3D (see, for example, http://www.eiscat3d.se) appears to provide additional details on spatial and temporal distribution of plasma density structures. On the other hand, EISCAT_3D measurements could be used to provide maps of TEC (as suggested in Lilensten and Cander (2003), Lilensten et al. (2005), and Jakowski et al. (2002) for example) as well as of rate of change of TEC with higher spatial and temporal resolution than what is available from standard TEC maps at present. The only limitation for EISCAT_3D would be the region covered (northern Scandinavia). However, in that region 
the measurements would be very relevant for precise satellite navigation and positioning used there in applications such as aviation, land surveying, property management, offshore drilling, amongst others.

Finally, additional experiments are needed in order to gather more evidence on possible layer-mixing mechanisms (of the type detected in Swartz et al., 2009, for example).

\section{Conclusions}

Measurements of GPS rates of change of TEC were compared with EISCAT observations from Troms $\emptyset$. The measurement campaign took place from 12 December 2011 until 16 December 2011 and was based on instruments operated by the EISCAT Scientific Association and the University of Bath. The EISCAT UHF radar in Troms $\varnothing$ was pointed towards a single GPS satellite all the time. The given PRN was followed during its orbit at steps of 5 min intervals over which the GPS satellite was crossing the radar line of sight. In order to increase the radar accuracy, an integration time of approximately $150 \mathrm{~s}$ was chosen as the best compromise between accuracy, temporal and spatial resolutions. GPS measurements were collected by means of standard GSV ionospheric monitors capable of outputting TEC values as well as signal components at $50 \mathrm{~Hz}$ sampling rate.

The agreement between the two types of instruments appeared evident in a case of isolated Es layer and ionisation enhancement possibly due to plasma patches transported over the line of sight.

The potential benefit from future EISCAT_3D measurements appeared to be indicated by the simple experiment described here. The benefit could be associated with an accurate tool for the refinement of 3-D tomography imaging based on satellite data as well as for the higher spatial and temporal resolution for equivalent maps of TEC and rate of change of TEC, which would prove very useful for applications based on precise satellite navigation and positioning.

The repetition of the present experiment during more active conditions could provide more details on the level of structuring, possible layer-mixing processes, the origin of scintillation-induced signal fluctuations within the weak scattering approximation, and the associated modelling.

\section{Appendix A}

\section{Temporal TEC fluctuations}

The tracked satellites (PRN 23) provided TEC measurements which were compared with the radar's. In view of the error connected with electron density profiles at $150 \mathrm{~s}$ integration time, the EISCAT TEC was calculated by integrating the electron density profiles from $70 \mathrm{~km}$ up to $500 \mathrm{~km}$. Because the interest was in the comparison between rates of changes of TEC (no absolute GPS slant TEC calibration was attempted here), the observation times needed to be as close as possible. While the GPS TEC values were supplied every $15 \mathrm{~s}$, the radar sample rate corresponded, instead, to the integration time used to retrieve the TEC over $150 \mathrm{~s}$. It has to be considered that, to follow the satellite, the radar antenna moved every $5 \mathrm{~min}$ and, because the movement takes a few seconds, the actual measurement time interval could be slightly smaller than $150 \mathrm{~s}$.

Furthermore, the two sample times were not aligned. There were about 10 GPS samples in each radar measurement interval (a rate of $15 \mathrm{~s}$ in about $150 \mathrm{~s}$ interval) which need to be reduced and aligned with the radar data according to a communal reference time (Fig. 3). The reference time $t_{\text {ref }}$ was then set as the central point within the radar integration time. The GPS samples, in the same reference time, were therefore calculated by averaging the total GPS samples contained within the radar integration time interval (Fig. 3). Assuming, for example, $L$ individual GPS samples within $150 \mathrm{~s}$ (radar integration time),

$\operatorname{TEC}^{\mathrm{GPS}}\left(t_{\mathrm{ref}}\right)=\frac{1}{L} \sum_{k=1}^{L} \operatorname{TEC}^{\mathrm{GPS}}\left(t_{\mathrm{GPS}}^{k}\left(t_{\mathrm{ref}}\right)\right)$,

where $k$ is index for $L$ elements in window centred about $t_{\text {ref }}$. Within the same reference time, $t_{\text {ref }}$, the GPS and radar measurements can be easily compared in terms of TEC variation. Thus, the time variation of the radar TEC is calculated as

$\nabla \mathrm{TEC}^{\mathrm{Rad}} \equiv \frac{\Delta \mathrm{TEC}^{\mathrm{Rad}}}{\Delta t}=\frac{\operatorname{TEC}^{\mathrm{Rad}}\left(t_{\mathrm{ref}}\right)-\mathrm{TEC}^{\mathrm{Rad}}\left(t_{\mathrm{ref}}-\Delta t\right)}{\Delta t}$,

where $\Delta t$ is the time step and is about $150 \mathrm{~s}$. Similarly, the TEC variation in time retrieved by the GPS is calculated as

$\nabla \mathrm{TEC}^{\mathrm{GPS}}=\frac{\Delta \mathrm{TEC}^{\mathrm{GPS}}}{\Delta t}=\frac{\mathrm{TEC}^{\mathrm{GPS}}\left(t_{\mathrm{ref}}\right)-\mathrm{TEC}^{\mathrm{GPS}}\left(t_{\mathrm{ref}}-\Delta t\right)}{\Delta t}$

and, because of the same reference time $t_{\text {ref }}$, the time interval $\Delta \mathrm{t}$ is the same as the radar one.

\section{Appendix B}

\section{Error analysis}

The purpose of this section is to provide more details about the specific error analysis performed on the radar data. The radar database supplies the error standard deviation $\varepsilon_{e^{-}}$associated with every measurement of electron content along the range $r$. Assuming that the errors are statistically i.i.d. (independent and identically distributed), it is possible to estimate the error in the total electron content $\varepsilon_{\mathrm{TEC}}$, i.e. the error in 
the indirect measurement of TEC:

$\varepsilon_{\mathrm{TEC}}(t)=\sqrt{\sum_{h=0}^{H-1} \varepsilon_{e^{-}}^{2}(t, h) \Delta r(h),}$

where $\Delta r(h)=r(h+1)-r(h), r(h)$ is the $h$-th range gate and $r(1)$ and $r(H)$ are the lower and upper range bounds calculated, respectively.

The error associated with $\nabla \mathrm{TEC}^{\mathrm{Rad}}(t)$ is as follows (using $t$ instead of $t_{\text {ref }}$ ):

$\varepsilon_{\nabla \operatorname{TEC}}(t)=\frac{1}{\Delta t} \sqrt{\varepsilon_{\nabla \mathrm{TEC}}^{2}(t)+\varepsilon_{\nabla \mathrm{TEC}}^{2}(t-\Delta t)}$.

For different ionospheric regions (D/E, F1 and F2 layers), the TEC derivative is obtained as

$$
\begin{aligned}
\nabla \operatorname{TEC}_{E / D}(t) & =\nabla \operatorname{TEC}_{70}(t)-\nabla \operatorname{TEC}_{160}(t) \\
\nabla \operatorname{TEC}_{F 1}(t) & =\nabla \operatorname{TEC}_{160}(t)-\nabla \operatorname{TEC}_{200}(t) \\
\nabla \operatorname{TEC}_{F 2}(t) & =\nabla \operatorname{TEC}_{200}(t),
\end{aligned}
$$

where $\nabla \mathrm{TEC}_{X}(t)$ is the temporal gradient in TEC measured from $X \mathrm{~km}$ altitude upwards (Eq. A2).

In this case the error deviation of the two arguments is no longer i.i.d. because the error along the common range is exactly the same. Thus the resulting error is only the difference between the two $\varepsilon_{\nabla T E C}$ :

$$
\begin{aligned}
\varepsilon_{\nabla \operatorname{TEC}_{E / D}}(t) & =\sqrt{\varepsilon_{\nabla \operatorname{TEC}_{70}}^{2}(t)-\varepsilon_{\nabla \operatorname{TEC}_{160}}^{2}(t)} \\
\varepsilon_{\nabla \operatorname{TEC}_{F 1}}(t) & =\sqrt{\varepsilon_{\nabla \operatorname{TEC}_{160}}^{2}(t)-\varepsilon_{\nabla \mathrm{TEC}_{200}}^{2}(t)} \\
\varepsilon_{\nabla \mathrm{TEC}_{F 2}}(t) & =\varepsilon_{\nabla \mathrm{TEC}_{200}(t) .}
\end{aligned}
$$

Acknowledgements. B. Forte's research activity at the University of Bath between October 2011 and May 2012 was supported by a Marie Curie Intra-European Fellowship within the 7th European Community Framework Programme. The research activity of F. Da Dalt, T. Panicciari, D. Stevanovic and M. Vuckovic was supported by a Marie Curie Initial Training Network (TRANSMIT) within the 7th European Community Framework Programme under Marie Curie Actions. B. Forte would like to thank I. McCrea (UK STFC) for precious discussions connected with the experimental setup. EISCAT is an international association supported by research organisations in China (CRIRP), Finland (SA), Germany (DFG, till end of 2011), Japan (NIPR and STEL), Norway (NFR), Sweden (VR), and the United Kingdom (STFC).

Topical Editor K. Hosokawa thanks two anonymous referees for their help in evaluating this paper.

\section{References}

Aikio, A., McCrea, I., and the EISCAT_3D Science Working Group: EISCAT_3D Science Case, Technical Document available at http://www.eiscat3d.se, accessed on 20 December 2012.
Bust, G. S. and Mitchell, C. N.: History, current state, and future directions of ionospheric imaging, Rev. Geophys., 46, RG1003, doi:10.1029/2006RG000212, 2008.

Chartier, A. T., Mitchell, C. N., and Jackson, D. R.: A 12-year comparison of MIDAS and IRI 2007 ionospheric Total Electron Content, Adv. Space Res., 49, 1348-1355, 2012.

Ciraolo, L., Azpilicueta, F., Brunini, C., Meza, A., and Radicella, S. M.: Calibration errors on experimental slant total electron content (TEC) determined with GPS, J. Geod., 81, 111-120, doi:10.1007/s00190-006-0093-1, 2007.

Davies, K.: Ionospheric radio propagation, Dover Publications Inc., 1965.

Foster, J. C., Coster, A. J., Erickson, P. J., Holt, J. M., Lind, F. D., Rideout, W., McCready, M., van Eyken, A., Barnes, R. J., Greenwald, R. A., and Rich, F. J.: Multiradar observations of the polar tongue of ionization, J. Geophys. Res., 110, A09S31, doi:10.1029/2004JA010928, 2005.

Jakowski, N., Sardon, E., Engler, E., Jungstand, A., and Klähn, D.: Relationships between GPS-signal propagation errors and EISCAT observations, Ann. Geophys., 14, 1429-1436, doi:10.1007/s00585-996-1429-0, 1996.

Jakowski, N., Heise, S., Wehrenpfennig, A., Schlüter, S., and Reimer, R.: GPS/GLONASS-based TEC measurements as a contributor for space weather forecast, J. Atmos.Sol.-Terr. Phys., 64, 729-735, 2002.

Johansson, G., Borg, J., Johansson, J., Lundberg Nordenvaad, M., and Wannberg, G.: Simulation of post-ADC digital beamforming for large aperture array radars, Radio Sci., 45, RS3001, doi:10.1029/2008RS004124, 2010.

Kirkwood, S. and Nilsson, H.: High-latitude Sporadic-E and other Thin Layers - the Role of Magnetospheric Electric Fields, Space Sci. Rev., 91, 579-613, doi:10.1023/A:1005241931650, 2000.

Lehtinen, M. S. and Huuskonen, A.: General incoherent scatter analysis and GUISDAP, J. Atmos. Terr. Phys., 58, 435-452, 1996.

Lilensten, J. and Cander, Lj. R.: Calibration of the TEC derived from GPS measurements and from ionospheric models using the EISCAT radar, J. Atmos. Sol.-Terr. Phys., 65, 833-842, 2003.

Lilensten, J., Cander, Lj. R., Rietveld, M. T., Cannon, P. S., and Barthélémy, M.: Comparison of EISCAT and ionosonde electron densities: application to a ground-based ionospheric segment of a space weather programme, Ann. Geophys., 23, 183189, doi:10.5194/angeo-23-183-2005, 2005.

Lunt, N., Kersley, L. L., Bishop, G. J., and Mazzella, A. J.: The contribution of the protonosphere to GPS total electron content: experimental measurements, Radio Sci., 34, 1273-1280, 1999.

Mannucci, A. J., Wilson, B. D., Yuan, D. N., Ho, C. H., Lindqwister, U. J., and Runge, T. F.: A global mapping technique for GPSderived ionospheric total electron content measurements, Radio Sci., 33, 565-582, doi:10.1029/97RS02707, 1998.

Meggs, R. W., Mitchell, C. N., and Spencer, P. S. J.: A comparison of techniques for mapping total electron content over Europe using GPS signals, Radio Sci., 39, RS1S10, doi:10.1029/2002RS002846, 2004.

Meggs, R. W., Mitchell, C. N., and Howells, V. S. C.: Simultaneous observations of the main trough using GPS imaging and the EISCAT radar, Ann. Geophys., 23, 753-757, doi:10.5194/angeo23-753-2005, 2005. 
Mitchell, C. N. and Spencer, P. S. J.: A three-dimensional time-dependent algorithm for ionospheric imaging using GPS, Ann. Geophys., 46, 687-696, 2003.

Moen, J., Carlson, H. C., Oksavik, K., Nielsen, C. P., Pryse, S. E., Middleton, H. R., McCrea, I. W., and Gallop, P.: EISCAT observations of plasma patches at sub-auroral cusp latitudes, Ann. Geophys., 24, 2363-2374, doi:10.5194/angeo-242363-2006, 2006.

Nygrén, T., Jalonen, L., Oksman, J., and Turunen, T.: The role of electric field and neutral wind direction in the formation of sporadicE-layers, J. Atmos. Terr. Phys., 46, 373-381, 1984.

Pokhotelov, D., Jayachandran, P. T., Mitchell, C. N., MacDougall, J. W., and Denton, M. H.: GPS tomography in the polar cap: comparison with ionosondes and in situ spacecraft data, GPS Solut., 15, 79-87, doi:10.1007/s10291-010-0170-z, 2011.

Schaer, S.: Mapping and predicting the Earth's ionosphere using the Global Positioning System, Geod.-Geophys. Arb. Schweiz, vol. 59, 1999.

Stolle, C., Lilensten, J., Schlüter, S., Jacobi, Ch., Rietveld, M., and Lühr, H.: Observing the north polar ionosphere on 30 October 2003 by GPS imaging and IS radars, Ann. Geophys., 24, 107113, doi:10.5194/angeo-24-107-2006, 2006.

Swartz, W. E., Kelley, M. C., and Aponte, N.: E- and F-region coupling between an intense sporadic $\mathrm{E}$ layer and a mesoscale traveling ionospheric disturbance, Ann. Geophys., 27, 2475-2482, doi:10.5194/angeo-27-2475-2009, 2009.
TRANSMIT, Training Research and Applications Network to Support the Mitigation of Ionospheric Threats: Marie Curie Initial Training Network, funded within the EU FP7, http://www. transmit-ionosphere.net, last access 2013.

Van Dierendonck, A. J., Hua, Q., and Klobuchar, J.: Ionospheric scintillation monitoring using commercial single frequency C/A code receivers, Proceedings of ION GPS 93, Salt Lake City, UT, 22-24 September, 1333-1342, 1993.

Yin, P., Mitchell, C. N., Spencer, P., McCrea, I., and Pedersen, T.: A multi-diagnostic approach to understanding high-latitude plasma transport during the Halloween 2003 storm, Ann. Geophys., 26, 2739-2747, doi:10.5194/angeo-26-2739-2008, 2008.

Yizengaw, E., Moldwin, M. B., Dyson, P. L., Fraser, B. J., and Morley, S.: First tomographic image of ionospheric outflows, Geophys. Res. Lett., 33, L20102, doi:10.1029/2006GL027698, 2006a.

Yizengaw, E., Moldwin, M. B., Komjathy, A., and Mannucci, A. J.: Unusual topside ionospheric density response to the November 2003 superstorm, J. Geophys. Res., 111, A02308, doi:10.1029/2005JA011433, 2006b. 